\title{
Observational and Modeling Study of Ice Hydrometeor Radar Dual-Wavelength Ratios
}

\author{
Sergey Y. Matrosov, Maximilian MaAhn, And GiJs de Boer \\ Cooperative Institute for Research in Environmental Sciences, University of Colorado Boulder, and \\ NOAA/Earth System Research Laboratory/Physical Sciences Division, Boulder, Colorado
}

(Manuscript received 23 January 2019, in final form 17 June 2019)

\begin{abstract}
The influence of ice hydrometeor shape on the dual-wavelength ratio (DWR) of radar reflectivities at millimeter-wavelength frequencies is studied theoretically and on the basis of observations. Data from dualfrequency ( $\mathrm{K}_{\mathrm{a}}-\mathrm{W}$ bands) radar show that, for vertically pointing measurements, DWR increasing trends with reflectivity $Z_{e}$ are very pronounced when $\mathrm{K}_{\mathrm{a}}$-band $Z_{e}$ is greater than about $0 \mathrm{~dB} Z$ and that DWR and $Z_{e}$ values are usually well correlated. This correlation is explained by strong relations between hydrometeor characteristic size and both of these radar variables. The observed DWR variability for a given level of reflectivity is as large as $8 \mathrm{~dB}$, which is in part due to changes in mean hydrometeor shape as expressed in terms of the particle aspect ratio. Hydrometeors with a higher degree of nonsphericity exhibit lower DWR values when compared with quasi-spherical particles because of near-zenith reflectivity enhancements for particles outside the Rayleigh-scattering regime. When particle mass-size relations do not change significantly (e.g., for lowrime conditions), DWR can be used to differentiate between quasi-spherical and highly nonspherical hydrometeors because (for a given reflectivity value) DWR tends to increase as particles become more spherical. Another approach for differentiating among different degrees of nonsphericity for larger scatterers is based on analyzing DWR changes as a function of radar elevation angle. These changes are more pronounced for highly nonspherical particles and can exceed $10 \mathrm{~dB}$. Measurements of snowfall spatiotemporally collocated with spaceborne CloudSat W-band radar and ground-based S-band operational weather radars also indicate that DWR values are generally smaller for ice hydrometeors with higher degrees of nonsphericity, which, for the same level of S-band reflectivity, exhibit greater differential reflectivity values.
\end{abstract}

\section{Introduction}

Millimeter-wavelength radars can provide valuable information on details solid precipitation microphysics. Such details can be useful for the enhancement of understanding on climate and ecosystems (e.g., Callaghan et al. 2011), in particular in remote regions (e.g., the Arctic) where quantitative information on snowfall properties is scarce. For example, snow plays an important role in the energy budget of the Arctic sea ice pack (e.g., Sturm et al. 2002) and the microclimate of tundra and alpine ecosystems (e.g., Wipf and Rixen 2010). Despite this importance, there are few observational constraints on the amount and type of snow particles in numerical models across a variety of scales. Additional insight into the properties of ice hydrometeors and how those properties change with

\footnotetext{
Corresponding author: Sergey Y. Matrosov, sergey.matrosov@ noaa.gov
}

weather conditions, season and aerosol properties could potentially improve the simulation of clouds and precipitation.

Several studies suggested utilizing the dual-wavelength ratio (DWR) for improving the accuracy of radar-based quantitative precipitation estimation (QPE) for snowfall and for retrieving microphysical properties of ice hydrometeors values (e.g., Matrosov 1998; Liao et al. 2005; Huang et al. 2019). Some studies extended this by using triple-frequency measurements for deriving two different DWR values (e.g., Kneifel et al. 2015; Chase et al. 2018; Leinonen et al. 2018). DWR, which is sometimes also called the dual-frequency ratio, is defined as the logarithmic difference between equivalent radar reflectivity factors $Z_{e}$ at two frequencies $\nu_{1}$ and $\nu_{2}$ $\left[\mathrm{DWR}(\mathrm{dB})=Z_{e \nu 1}(\mathrm{dBZ})-Z_{e \nu 2}(\mathrm{dBZ})\right.$, with $\left.\left.\nu_{1}<\nu_{2}\right)\right]$. When scatterers are not small enough relative to the radar wavelength at least at the higher frequency, backscatter is not scaled as $\nu^{4}$ (i.e., it is outside the Rayleigh scattering regime at $\nu_{2}$ ). In this case DWR can provide 
additional information on ice hydrometeor characteristic size (e.g., median volume/mass or effective size), which represents the entire particle size distribution (PSD).

One important DWR property is its relatively low sensitivity to variations in ice particle bulk density (e.g., Matrosov 1998). Particle shape dependence of the DWR, however, can be significant. This is especially true for higher frequencies when the particle size-wavelength ratios could be particularly large. Both airborne and ground-based high-frequency dual-wavelength radar systems (e.g., $\mathrm{K}_{\mathrm{a}}$ and/or W bands) are increasingly used to remotely sense ice hydrometeor microphysical properties and snowfall QPE (Liao et al. 2008; Matrosov et al. 2017; Mason et al. 2018). Unlike for liquid hydrometeors, radar signal attenuation due to ice hydrometeors is relatively small, meaning that high-frequency radars are well suited for ice microphysical studies. Often, beam pointing of such radars is limited to zenith for ground-based systems or nadir for airborne and spaceborne systems.

Because DWR depends on hydrometeor shape (Matrosov 1993; Matrosov et al. 2005), snowfall property retrieval techniques utilizing the DWR usually assume an average ice hydrometeor shape (e.g., Mason et al. 2018; Huang et al. 2019). The shape parameter is usually expressed as a particle aspect ratio, which is defined as a ratio of hydrometeor minor and major dimensions. Dual-wavelength effects become stronger as particle size-wavelength ratio increases. As a result, the DWR hydrometeor shape sensitivity is especially strong when the shorter radar wavelength is at $\mathrm{W}$ band $(\sim 94 \mathrm{GHz})$, which is typically the highest frequency used in meteorological radars.

An important practical use of DWR measurements involves the ability to estimate hydrometeor sizes. There are also indications (e.g., Matrosov and Heymsfield 2017) that characteristic size parameters of atmospheric ice particles are well correlated with absolute reflectivity factor (hereinafter just reflectivity), so a certain correspondence between reflectivity and DWR can be expected. One objective of the current study is to analyze such correspondence from both theory and observational data, and to establish at what reflectivity values, on average, DWR measurements contain information on particle properties. Another objective is to assess if and under what conditions DWR can be potentially used as some indicator of general particle shape.

The central focus of this study is on the millimeterwavelength DWR. Cloud radars operating at such wavelengths are increasingly used for atmospheric ice measurements. Observational data mostly came from the second-generation U.S. Department of Energy (DOE) scanning Atmospheric Radiation Measurement (ARM) cloud radar (SACR-2) operating at $\mathrm{K}_{\mathrm{a}^{-}}(\sim 35 \mathrm{GHz})$ and
W-band $(\sim 94 \mathrm{GHz})$ frequencies. In $2016-17$, this radar was deployed at the Oliktok Point $\left(70.495^{\circ} \mathrm{N}, 149.886^{\circ} \mathrm{W}\right)$ ARM Mobile Facility 3 (AMF3). The SACR-2 data are available from the ARM Data Center (Matthews et al. 2016a,b).

\section{Correspondence between reflectivity and DWR measurements}

\section{a. Observational data}

Figure 1 shows scatterplots of $\mathrm{K}_{\mathrm{a}}-\mathrm{W}$-band DWR versus $\mathrm{K}_{\mathrm{a}}$-band reflectivity $Z_{e}$ from vertically pointing SACR-2 measurements during three October 2016 $(15,18$, and 21 October) and three May 2017 (9, 14, and 24 May) stratiform snowfall events. The data were thresholded at a 3-dB signal-to-noise ratio and an absolute value of mean Doppler velocity of $0.1 \mathrm{~m} \mathrm{~s}^{-1}$ to mitigate clutter. The SACR-2 $\mathrm{K}_{\mathrm{a}^{-}}$and $\mathrm{W}$-band radar beams are closely matched ( $\sim 0.3^{\circ}$ beamwidth). Range sampling is $15 \mathrm{~m}$ for both channels and the closest range gate is at a distance of $0.375 \mathrm{~km}$. The measurements shown in Fig. 1 correspond to radar gates located below $0.5 \mathrm{~km}$, which was generally lower than the base of supercooled liquid layers estimated from a collocated ceilometer (not shown). Temperatures thorough the atmospheric column generally were below freezing. Using these lowest radar gates results in minimization of differential attenuation due to cloud liquid.

Radar measurements were corrected for gaseous attenuation using an approach described by Matrosov and Turner (2018) and air pressure, humidity and temperature vertical profiles from interpolated radiosonde soundings at the AMF3 location. The effects of a relative miscalibration between the SACR-2 $\mathrm{K}_{\mathrm{a}^{-}}$and W-band channels were accounted for by introducing a DWRrelative correction term, which was calculated assuming that gaseous attenuation-corrected reflectivities at both frequencies are equal for small reflectivity values $\left(Z_{e}<-15 \mathrm{dBZ}\right)$. At these low reflectivities, it is expected that particles are small compared to both wavelengths and $\mathrm{DWR} \approx 0 \mathrm{~dB}$. The DWR-relative correction term was generally less than about $0.7 \mathrm{~dB}$ for the events considered in this study. The absolute calibration of the W-band SACR-2 channel was verified by intercomparing with the spaceborne CloudSat W-band radar during the satellite overpasses in the close proximity $(\sim 3 \mathrm{~km})$ of the AMF3 location. The corresponding intercomparisons indicated that the SACR-2 absolute calibration was within $\sim 2 \mathrm{~dB}$ of the CloudSat radar measurements.

Figure 1 illustrates that DWR and absolute reflectivity are, on average, strongly correlated, although the DWR variability for a given value of $Z_{e}$ is very high. Shapes of 

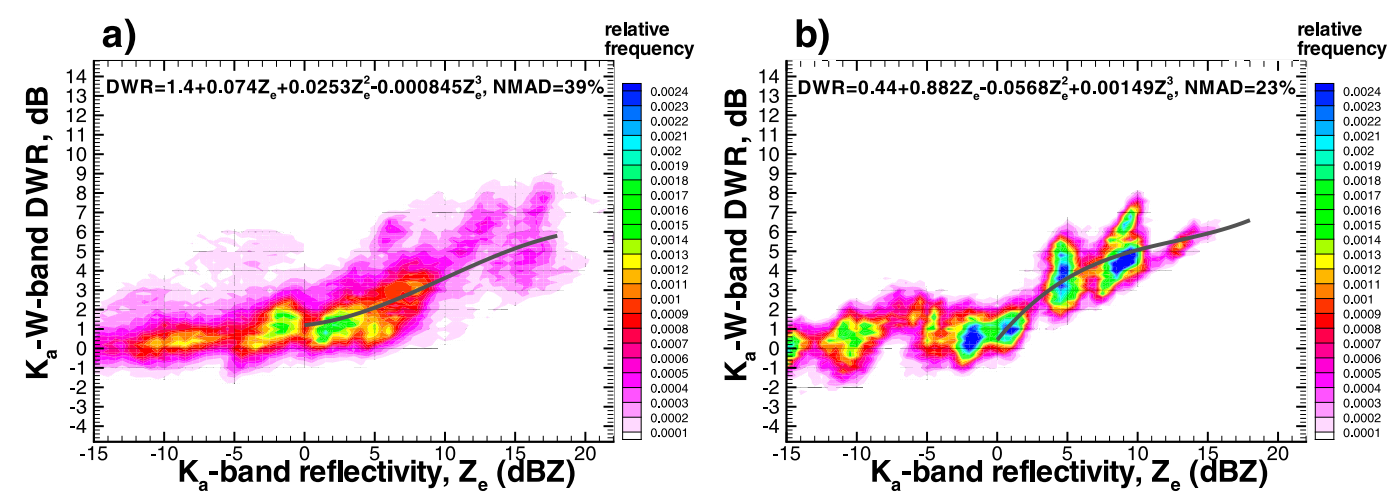

FIG. 1. Scatterplots of $K_{a}-W$ band DWR and $K_{a}$-band reflectivity measurements during snowfall events at the AMF3 site during (a) October 2016 and (b) May 2017 events. Polynomial best fits for $Z_{e}\left(\mathrm{~K}_{\mathrm{a}}\right)>0 \mathrm{~dB} Z$ are depicted. Values for normalized mean absolute difference $\left(\mathrm{NMAD}=100 \% \times\left\langle\left|\mathrm{DWR}-\mathrm{DWR}_{\mathrm{fit}}\right|\right\rangle /\langle\mathrm{DWR}\rangle\right.$, where the angle brackets denote averaging) are also shown.

DWR $-Z_{e}$ data scatter distributions are similar for October 2016 and May 2017 events. An average correspondence between DWR and $Z_{e}$ is not surprising since both variables are related to ice hydrometeor characteristic size. When $Z_{e}$ is less than about $0 \mathrm{dBZ}$, DWR exhibits rather small variability around $0 \mathrm{~dB}$ reflecting the fact that scattering at both radar wavelengths is mostly scaled as $\nu^{4}$. For larger reflectivities $\left(\sim Z_{e}>0 \mathrm{~dB} Z\right)$, DWR noticeably increases with $Z_{e}$, which suggests that a $0-\mathrm{dB} Z$ value may be a reasonable threshold at which the $\mathrm{K}_{\mathrm{a}}-\mathrm{W}$-band DWR becomes meaningful. For $\mathrm{K}_{\mathrm{a}}$-band $Z_{e}>0 \mathrm{~dB} Z$, the power-law correlation coefficients between DWR and $Z_{e}$ are 0.68 and 0.76 for the October 2016 and May 2017 events, respectively.

\section{b. Modeling $D W R-Z_{e}$ correspondences}

Modeling of reflectivity values (in linear units) was performed for in situ ice hydrometeor PSDs observed during the Indirect and Semi-Direct Aerosol Campaign (ISDAC) in Alaska using two-dimensional particle probes (McFarquhar et al. 2011; Maahn et al. 2015):

$$
Z_{e}=\lambda^{4} \pi^{-5}|(\varepsilon+2) /(\varepsilon-1)|^{2} \sum_{i} N_{i}\left(D_{i}\right) \sigma_{i}\left(D_{i}\right),
$$

where $\lambda$ is the radar wavelength, $\varepsilon$ is the dielectric constant of water, $N_{i}\left(D_{i}\right)$ and $\sigma_{i}\left(D_{i}\right)$ are particle concentrations and backscatter cross sections for the $i$ th bin size $D_{i}$ (given in terms of particle maximum dimensions), and the summation in Eq. (1) is performed for all size bins of a probe.

Backscatter cross sections $\sigma_{i}$ were calculated with the Passive and Active Microwave Transfer (PAMTRA) radar simulator (Maahn et al. 2015; Maahn and Löhnert 2017; available at https://github.com/igmk/pamtra) using the self-similar Rayleigh-Gans approximation (SSRG; Hogan and Westbrook 2014). Even though a spheroidal scattering model has some limitations in describing scattering properties of single pristine crystals with very low aspect ratios (e.g., Schrom and Kumjian 2018), bulk scattering estimations with SSRG are in very good agreement with discrete dipole approximation calculations of particle backscatter cross sections. Oblate spheroidal shapes with different aspect ratios $r$ were further assumed because prolate (columnar) type ice particles are observed (as a dominant particle type) significantly less frequently than oblate type shapes (e.g., Marchand et al. 2013). Note that a general distinction between oblate and prolate shapes is readily available from scanning polarimetric radar measurements (e.g., Matrosov 1991; Reinking et al. 2002). Pristine oblate crystals (e.g., dendrites and hexagonal plates) are also readily identifiable from polarimetric measurements.

The main focus in this study is on irregular ice particles ( $r$ is greater than about 0.2 ), which have a common occurrence and often are a dominant habit (e.g., Korolev and Isaac 1999). While each irregular ice particle is unique in shape, particle aspect ratio is one single quantitative parameter, which is customary used for describing particle general shape (e.g., Garrett et al. 2012). The spheroidal model allows for analyzing variability in radar parameters as aspect ratios change. The existing scattering databases (even though they are more accurate for a given particular particle shape) usually have a small amount of modeled habits and aspect ratio realizations (e.g., Lu et al. 2016), so a potential analysis of scattering properties of irregular particles as a function of aspect ratios is limited.

Though $\varepsilon$ in Eq. (1) is frequency dependent, a typical value for $|(\varepsilon+2) /(\varepsilon-1)|^{-2}=0.93$ was assumed so that DWR for small particle (relative to both wavelengths) populations is $0 \mathrm{~dB}$. It was also assumed that particles are horizontally aligned, based on previous findings 

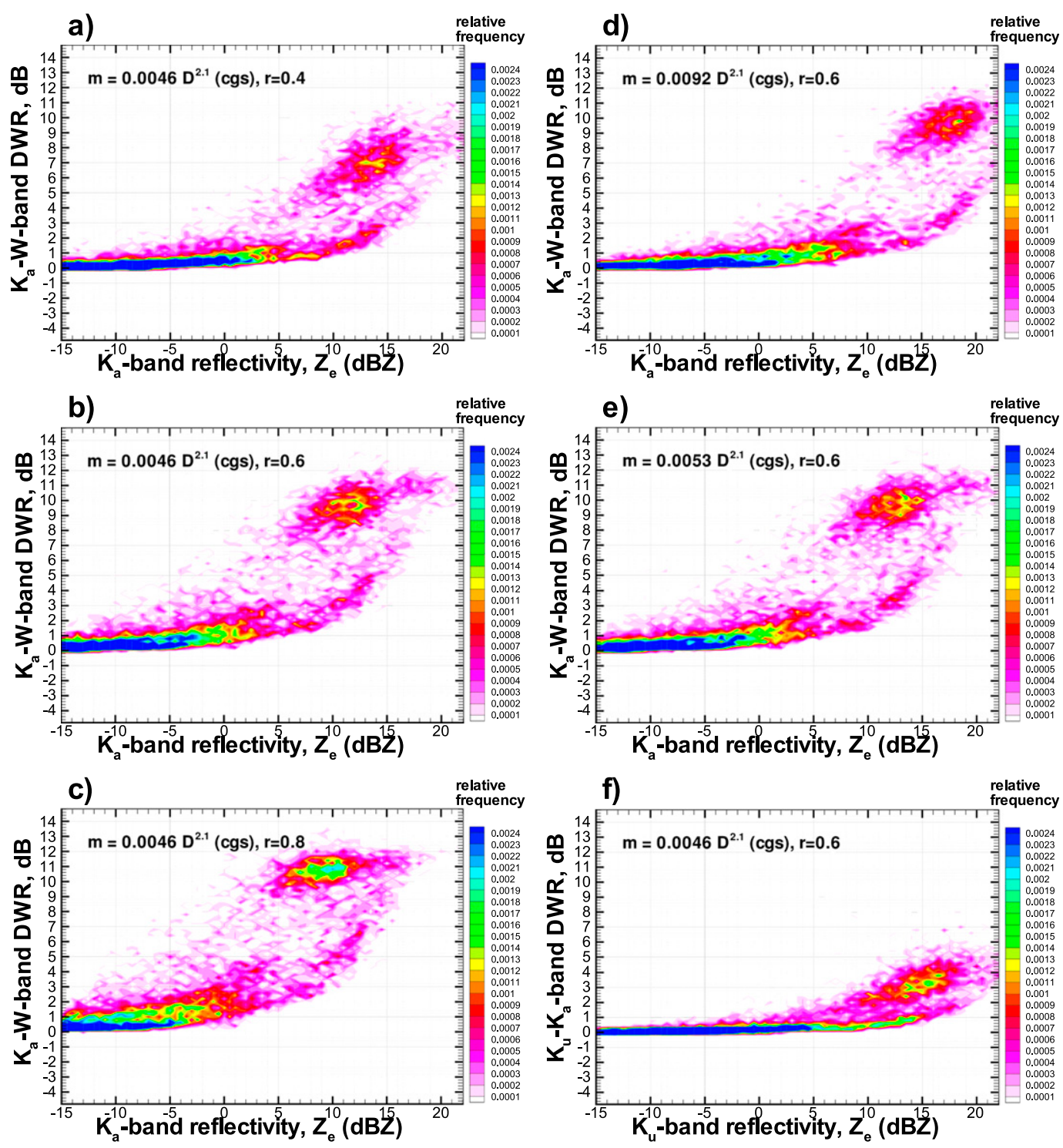

FIG. 2. Modeling results of DWR $-Z_{e}$ scatterplots using ISDAC PSDs for $\alpha=0.0046$ and $\beta=2.1$ along with particle aspect ratio $r=$ (a) 0.4 , (b),(f) $r=0.6$, or (c) $r=0.8$; (e) $\alpha=0.0053$ and $\beta=2.1$ along with $r=0.6$; or (d) $\alpha=$ 0.0092 and $\beta=2.1$ along with $r=0.6$. The $\alpha$ and $\beta$ are in cgs units. The $\mathrm{K}_{\mathrm{a}}-\mathrm{W}$ frequencies are used in (a) $-(\mathrm{e})$, and $\mathrm{K}_{\mathrm{u}}-\mathrm{K}_{\mathrm{a}}$ frequencies appear in (f).

from polarimetric radar measurements (e.g., Hogan et al. 2012; Melnikov 2017) demonstrating that typical particle standard deviations from preferential horizontal orientation are usually rather small $\left(\sim 10^{\circ}-20^{\circ}\right)$. Backscatter of individual particles depends on particle density, which is determined by their mass-size relations (i.e., $m-D$ relations) that are typically expressed by power-law approximations:

$$
m=\alpha D^{\beta},
$$

where $\alpha$ and $\beta$ are empirical constants. When modeling radar variables using the SSRG approximation, solid ice inclusions into the spheroidal particle shape are introduced and the total mass is constrained by Eq. (2). Backscatter is calculated depending on the area of solid ice intersected by the cross section of a particle that is perpendicular to the viewing direction (Hogan and Westbrook 2014).

Von Lerber et al. (2017) found that median values of the prefactor $\alpha$ and the exponent $\beta$ in Eq. (2) for unrimed and lightly rimed falling ice particles near the ground are 0.0046 and 2.1 (cgs units hereinafter), respectively. Figures $2 \mathrm{a}-\mathrm{c}$ show simulated DWR $-Z_{e}$ correspondence for a $\mathrm{K}_{\mathrm{a}-} \mathrm{W}$-band combination. 
These calculations assume the values of $\alpha$ and $\beta$ discussed above and are shown for particle aspect ratios $0.4,0.6$, and 0.8 . This is an approximate range of particle mean aspect ratios that have been frequently observed using direct sensors and polarimetric radar-based retrievals including parts of the 21 October 2016 event when in situ sampling aloft was available (Matrosov et al. 2017). Correlation coefficients between modeled DWR and $Z_{e}\left(\mathrm{~K}_{\mathrm{a}}\right)$ are in the range of $0.60-0.74$ for $Z_{e}\left(\mathrm{~K}_{\mathrm{a}}\right)>0 \mathrm{~dB} Z$, which is comparable to those from observations. As evident from these figures, populations of hydrometeors with higher degree of nonsphericity (i.e., with smaller $r$ values) exhibit smaller DWRs for a given reflectivity. This is due to the zenith/nadir reflectivity enhancement effect (relative to the slant viewing), which is observed for larger nonspherical particles (e.g., Matrosov et al. 2012; Marchand et al. 2013). This effect is much stronger at $\mathrm{W}$ band than at $\mathrm{K}_{\mathrm{a}}$ band; thus it generally causes a decrease of DWR as particles with larger sizewavelength ratios become more nonspherical. For extreme cases (e.g., larger single dendrites), W-band zenith reflectivity enhancements can be as high as $\sim 10 \mathrm{~dB}$ (Matrosov et al. 2012).

A comparison of Figs. 1a and $1 \mathrm{~b}$ and $2 \mathrm{a}-\mathrm{c}$ shows that there is an approximate agreement between the data scatter areas for observed and modeled data. Theoretical DWR values, however, are all positive, while the observational DWRs can be negative because of some residual relative calibration uncertainties and measurement noise. This is particularly true during extreme W-band zenith backscatter enhancements resulting from particles with higher degree of nonsphericity aligned in a nearly horizontal fashion.

Ice crystal riming causes the prefactor $\alpha$ in Eq. (2) to increase while the exponent $\beta$ does not change significantly until extreme riming transitions the ice crystals to graupel particles (Erfani and Mitchell 2017; von Lerber et al. 2017). This results in an increase of particle bulk density that elevates radar reflectivities at both frequencies although DWR changes little. To illustrate a relative independence of DWR to particle bulk density, Fig. 3 shows ISDAC PSD-based modeling results of DWR, when the prefactor $\alpha$ is increased by a factor of 2 (i.e., $\alpha=0.0092$ ), as compared with a low-rimed particle case (i.e., $\alpha=0.0046$ ).

To evaluate the influence of strong hydrometeor riming and variability in mass-size relations, Fig. 2 also shows modeling results associated with an increase in the prefactor $\alpha$ to 0.0053 (Fig. 2e) and to 0.0092 (Fig. 2d) for mean particle aspect ratio of 0.6. The mass-size relationship $m=0.0053 D^{2.1}$ corresponds to a median relation found by von Lerber et al. (2017) for moderately rimed snow crystals associated with clouds with

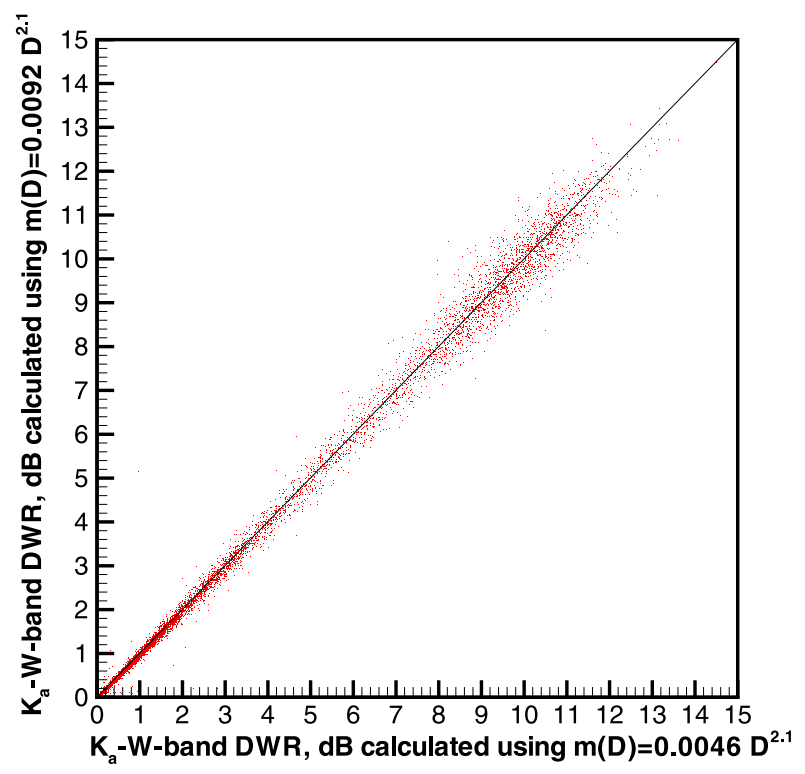

FIG. 3. Comparisons of dual-wavelength ratio modeling results using ISDAC PSDs and assuming different particle mass-size relations ( $m=0.0046 D^{2.1}$ and $m=0.0092 D^{2.1}$, in cgs units) for the aspect ratio of 0.6 .

a supercooled liquid water path (LWP) between 100 and $320 \mathrm{~g} \mathrm{~m}^{-2}$. This relation is practically identical to the one found to provide the best agreement between total mass obtained by integrating PSD data and that from concurrent counterflow virtual impactor measurements in a wide range of ice clouds and precipitation (Heymsfield et al. 2013). A prefactor value of 0.0092 would be associated with significant riming, with the rimed mass contributing to one-half of the total snow particle mass.

A comparison of Figs. $2 b$ and $2 e$ reveals that relatively small variations of the prefactor in $m-D$ relations cause only a small shift of the general data scatter area in the DWR $-Z_{e}$ plane and that DWR dependence on aspect ratio remains a major factor in changes of DWR for a given radar reflectivity. A large increase in particle mass due to riming (Fig. $2 d$ vs Fig. $2 b$ ) causes a relatively significant shift in the DWR-reflectivity relationship, moving data points toward higher reflectivities by approximately $5 \mathrm{~dB}$ for a given DWR. Shifting DWR $-Z_{e}$ points can be potentially used to identify riming. Modeling with a lower-frequency pair (i.e., $\mathrm{K}_{\mathrm{u}}-\mathrm{K}_{\mathrm{a}}$-band frequencies) employed by the Global Precipitation Mission satellite; Fig. 2f) results in significantly lower DWR values in comparison with the $\mathrm{K}_{\mathrm{a}}-\mathrm{W}$-band pair. For reliable DWR-based retrievals, lower-frequency $\left(\mathrm{K}_{\mathrm{u}}\right.$ band $\sim 13.6 \mathrm{GHz}$ ) reflectivity for this pair should be on average larger [e.g., $Z_{e}\left(\mathrm{~K}_{\mathrm{u}}\right)>$ 5-10 dBZ]. 

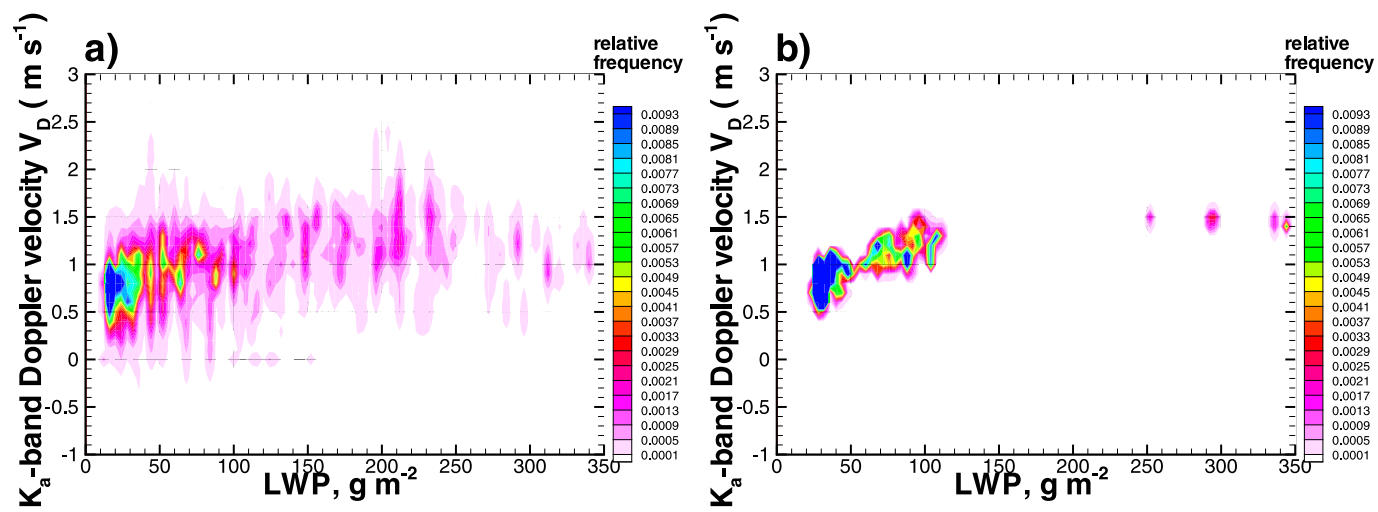

FIG. 4. Scatterplots of LWP and $\mathrm{K}_{\mathrm{a}}$-band vertical Doppler velocity measurements for snowfall at the AMF3 site during (a) October 2016 and (b) May 2017 events.

\section{Liquid water path and vertical mean Doppler velocity observations}

As mentioned above, riming causes changes in particle mass-size relations. Several previous studies (e.g., Mosimann 1995; Vogel and Fabry 2018) showed that rimed ice particles fall at speeds that are generally greater than about $1.5 \mathrm{~m} \mathrm{~s}^{-1}$ as expressed in the mean Doppler velocity measured by vertically pointing X-band $(\sim 9 \mathrm{GHz})$ radars. On average, vertical air motions in stratiform precipitation are very small relative to snowfall particle fall velocities and can therefore be neglected for larger values of vertical Doppler velocities $V_{D}$ (e.g., $>1 \mathrm{~m} \mathrm{~s}^{-1}$ ). Von Lerber et al. 2017 suggested a use of LWP inferred from microwave radiometer (MWR) measurements as a proxy for degree of riming. To investigate the role of riming, Fig. 4 shows frequency scatterplots of SACR-2 $\mathrm{K}_{\mathrm{a}}$-band vertical Doppler velocities $V_{D}$ and AMF3 MWR-based retrievals of LWP. The depicted $V_{D}$ values are adjusted to their expected values near the ground to minimize the effect of fall velocity changes due to changes in air density with height (Vogel and Fabry 2018):

$$
V_{D}=\left(\rho_{h} / \rho_{o}\right)^{0.5} V_{\mathrm{Dm}},
$$

where $V_{\mathrm{Dm}}$ is the observed Doppler velocity and $\rho_{h}$ and $\rho_{o}$ are air density at the observation height calculated from interpolated radiosonde data and that calculated at a standard atmospheric pressure at the surface $(1013 \mathrm{hPa})$.

It can be seen from Fig. 4 that there is a certain correlation between LWP and $\mathrm{K}_{\mathrm{a}}$-band mean vertical Doppler velocities. The corresponding correlation coefficients are 0.46 and 0.61 for the October and May events, correspondingly. For the vast majority of the data, $V_{D}<1.5 \mathrm{~m} \mathrm{~s}^{-1}$ and LWP $<250 \mathrm{~g} \mathrm{~m}^{-2}$, suggesting that no significant riming occurred. Although it is expected that $\mathrm{K}_{\mathrm{a}}$-band Doppler velocities could be somewhat lower than those at $\mathrm{X}$ band because of nonRayleigh scattering effects in larger particle populations, the difference between them is not expected to be significant. This is illustrated in Fig. 5, where ISDAC PSD-based model values of $V_{D}$ at $\mathrm{K}_{\mathrm{a}}$ and $\mathrm{X}$ band are shown for theoretical calculations with PAMTRA using the $m=0.0046 D^{2.1}$ relation and the particle fall velocity estimation approach from Heymsfield and Westbrook (2010).

\section{DWR as a possible indicator of general hydrometeor shape}

As seen from the observational results presented in Fig. 1, the variability of DWR values for approximately the same level of $\mathrm{K}_{\mathrm{a}}$-band reflectivity can be up to approximately $8 \mathrm{~dB}$. Even though particle characteristic size strongly influences DWR, the fact that significant DWR variability exists for a given reflectivity value suggests that other factors also strongly impact the DWR. This is because reflectivity also is well correlated with characteristic size of PSD (e.g., Matrosov and Heymsfield 2017), so constraining reflectivity, to a certain degree, also constrains the particle characteristic size.

The modeling results presented in Fig. 2 indicate that the hydrometeor aspect ratio, which is a proxy for a particle general shape, is an important factor in determining DWR variability at a given reflectivity value. In addition to aspect ratio, changes to the particle mass-size relation (e.g., due to riming processes) and PSD details also alter DWR. For particles with little or no riming particles, however, the effect of the $m-D$ variability at a given reflectivity level may be modest. It is instructive to evaluate in more detail how 


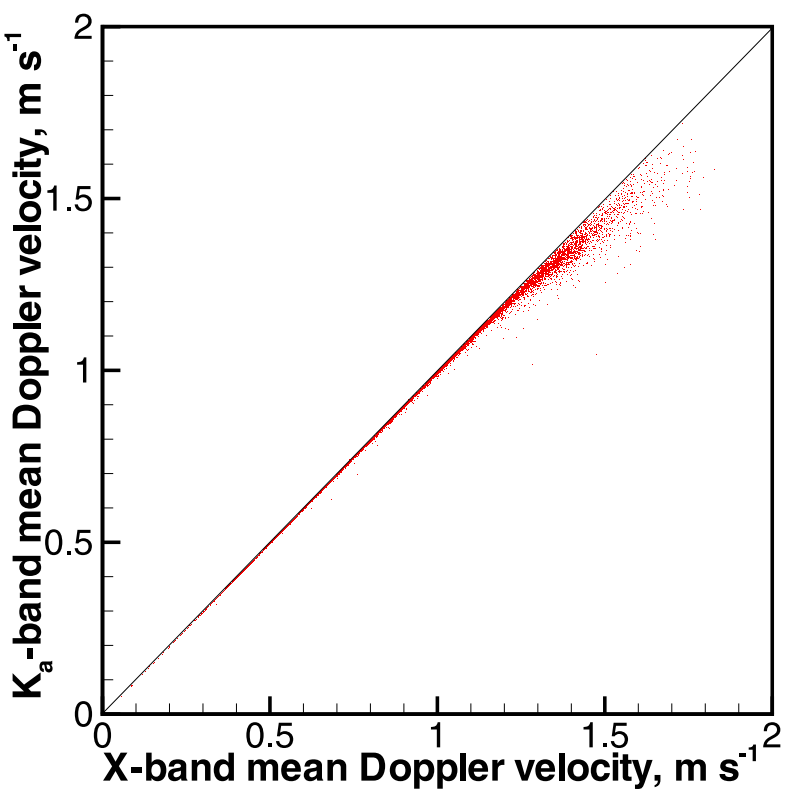

FIG. 5. Comparisons of vertical Doppler velocity modeling results using ISDAC PSDs and assuming the $m=0.0046 D^{2.1}$ (cgs units) mass-size relation.

differing hydrometeor shapes influence $\mathrm{K}_{\mathrm{a}}-\mathrm{W}$-band DWR and also changes in DWR-lower-frequency reflectivity relations.

The AMF3 SACR-2 was programmed to complete a variety of sampling scans, with a repeat cycle of $30 \mathrm{~min}$ (e.g., Matrosov et al. 2017). At 22 and 52 min after every hour, the radar was pointed vertically for $5 \mathrm{~min}$ at a time. Figure 6 shows the radar measurements at altitudes of less than $0.5 \mathrm{~km}$ from four representative vertical pointing periods when $\mathrm{K}_{\mathrm{a}}$-band reflectivity was changing between approximately 0 and $10 \mathrm{dBZ}$. For these periods, Fig. 6 also shows images of typical particles taken by a ground-based multiangle snowflake camera (MASC; Garrett et al. 2012; Maahn 2019), which was deployed at the AMF3 near the SACR-2. To account for the time required for radar-observed ice particles to reach the ground, MASC images with time stamps between 1255 and 1305 , between 1555 and 1605 , between 1625 and 1705, and between 1925 and 2005 UTC were assumed to be representative of Fig. 6 periods $a, b, c$, and $d$. While only a few MASC images (i.e., 3-7) were available for each of the periods during the 15 October 2016 event, several dozens of them were available for period $a$ on 24 May 2017. Based on the MASC data, little to no riming was observed.

The two consecutive 5 -min periods on 15 October 2016 (periods $b$ and $c$ in Fig. 6), are characterized by relatively small DWR values ( $<3 \mathrm{~dB}$ or so) and a small increase of DWR with reflectivity. Practically all MASC images during these periods indicate that the dominant particles were mostly nonspherical, including dendrite-type hydrometeors with some evidence of aggregation. The mean MASC-based aspect ratios during these times were around 0.4 , although these MASC aspect ratio values could be overestimated as the images are not generally aligned with the dendrite plane. It is possible that particle alignments captured by the MASC differ from those during particle free fall. Later on 15 October 2016 (period $d$ in Fig. 6) observed particles
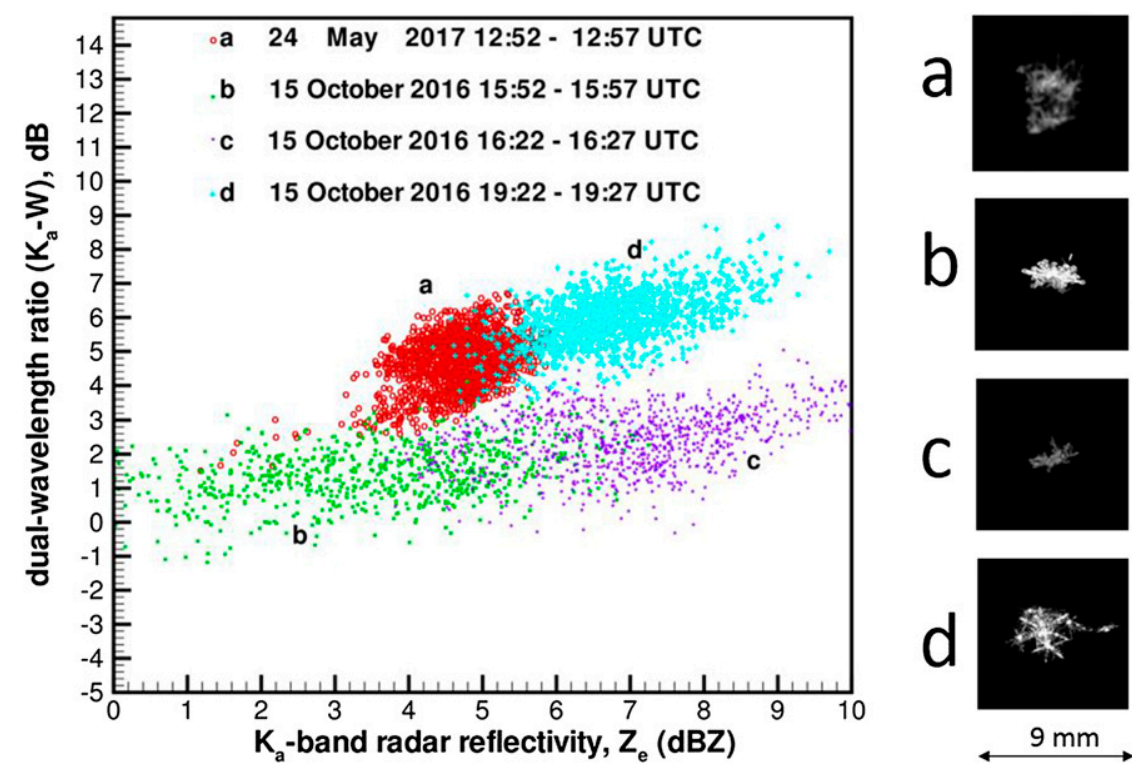

FIG. 6. DWR- $Z_{e}$ scatterplots during four different periods of SACR-2 vertical beam measurements, and typical MASC images of snow particles corresponding to these periods. 

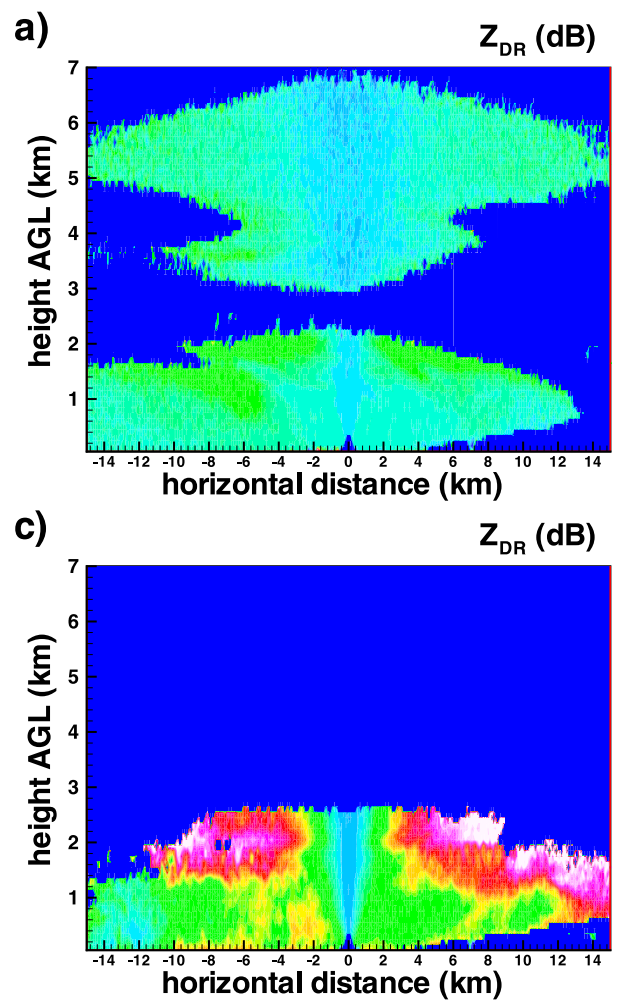
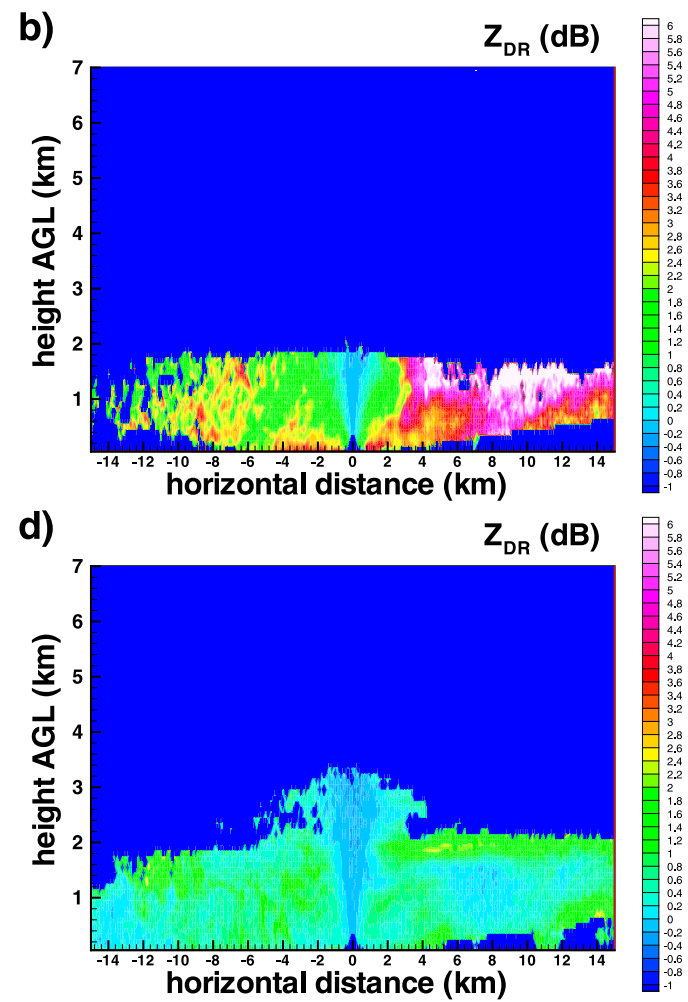

FIG. 7. RHI cross sections of $\mathrm{K}_{\mathrm{a}}$-band SACR-2 $Z_{\mathrm{DR}}$ measurements at (a) 1305 UTC 24 May 2017, (b) 1605 UTC 15 Oct 2016, (c) 1635 UTC 15 Oct 2016, and (d) 1935 UTC 15 Oct 2016. Positive distances from the radar site correspond to the $135^{\circ}$ azimuth direction, and negative distances correspond to the $225^{\circ}$ azimuth direction.

were more spherical (i.e., having mean MASC aspect ratios greater than 0.6) and of aggregate type. The corresponding DWR values during this period were significantly higher (up to about $8 \mathrm{~dB}$ ). Similarly, aggregate particles with MASC aspect ratios greater than 0.6 were also observed on 24 May 2017 between 1252 and 1257 UTC (period $a$ in Fig. 6). The data from this period are aligned well with those for more-spherical particles during the period $d$ on 15 October 2016.

Overall, the DWR values for more-spherical particles are noticeably greater than those observed for particles during periods $b$ and $c$ at a given range of reflectivities, thus confirming the theoretical estimates (Figs. 2a-c). The observed rate of the DWR increase with reflectivity is also more pronounced during times featuring more-spherical particles than during times with highly nonspherical particles. Negative DWR values (in the logarithmic scale) are possible for highly nonspherical particles when zenith reflectivity enhancements in the $\mathrm{W}$ band are very strong and some measurement noise is present. Note also that absolute reflectivities in Fig. 6 are mostly smaller than about $9-10 \mathrm{~dB} Z$ and therefore are in a range where DWR values calculated using other wavelength pairs (e.g., $\mathrm{K}_{\mathrm{u}}-\mathrm{K}_{\mathrm{a}}$ band) are likely to be very small and with limited variability, and therefore probably not very informative (see Fig. 2f).

The presence of more-nonspherical hydrometeors in the vicinity of the AMF3 location during the $b$ and $c$ periods relative to the $a$ and $d$ periods is also supported by polarimetric radar measurements. Figure 7 shows range-height indicator (RHI) $\mathrm{K}_{\mathrm{a}}$-band SACR-2 measurements of differential reflectivity $Z_{\mathrm{DR}}$. These four RHI scans were performed a few minutes after the corresponding periods of vertically pointing radar measurements depicted in Fig. 6. Changes of $Z_{\mathrm{DR}}$ resulting from changes in the radar elevation angle generally do not exceed $1 \mathrm{~dB}$ for 24 May 2017 ( $\sim 1305$ UTC, just after period $a$ ) and 15 October $2016(\sim 1935$ UTC, just after period $d$ ) scans indicating rather spherical particles. Higher $Z_{\mathrm{DR}}$ values are found only near cloud top. A strong dendritic signatures (i.e., $Z_{\mathrm{DR}}$ values up to about 6-7 dB for slant beam viewing) are present at the upper parts of the radar echo for 15 October $2016(\sim 1605$, just after period $b$ and $\sim 1635$ UTC, just after period $c$ ). Slant viewing differential reflectivities near the surface for these scans are smaller compared to higher up in the cloud, but they are still significantly larger than those in 

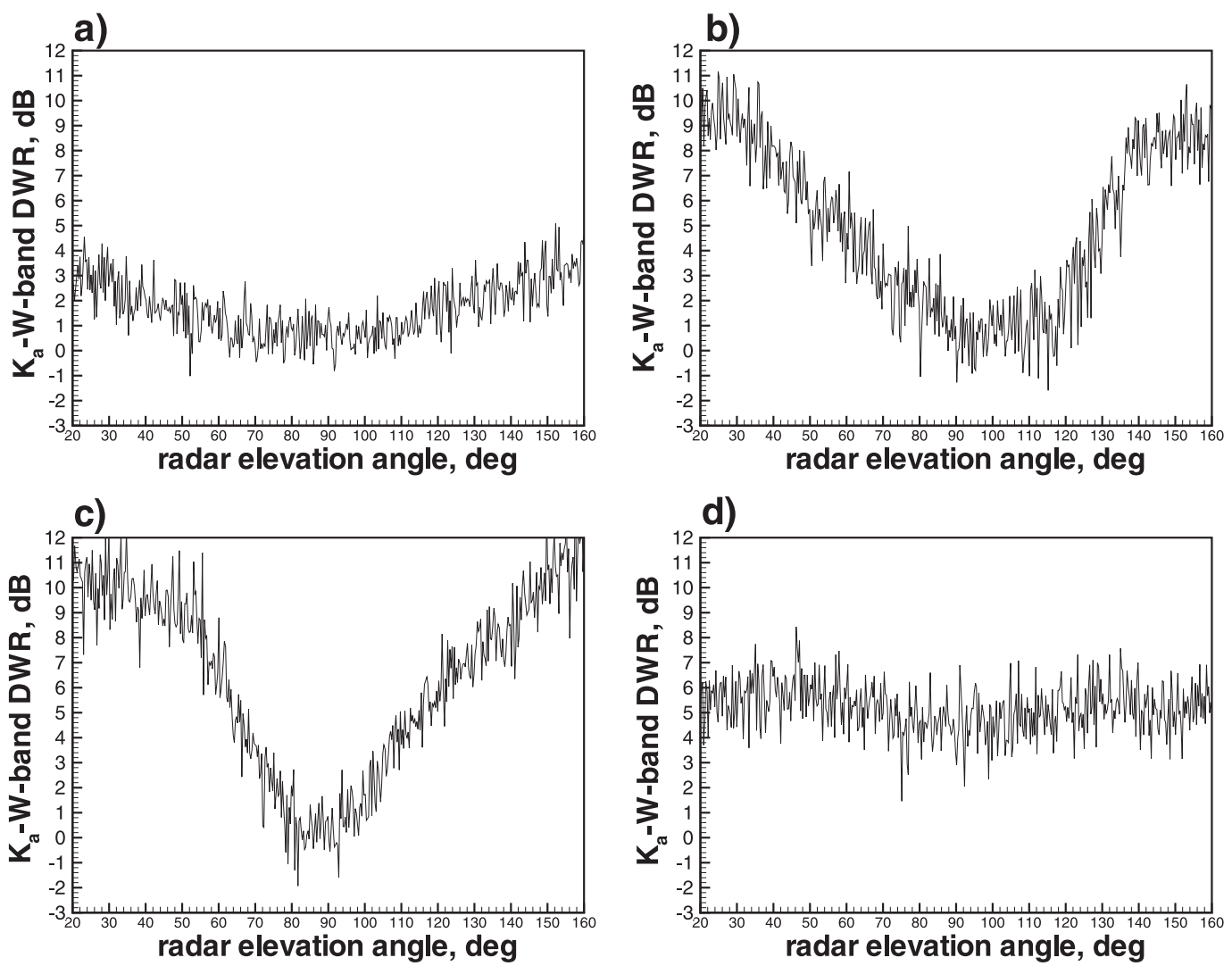

FIG. 8. Elevation-angle dependencies of DWR at a range of $0.4 \mathrm{~km}$ for (a) 1305 UTC 24 May 2017, (b) 1605 UTC 15 Oct 2016, (c) 1635 UTC 15 Oct 2016, and (d) 1935 UTC 15 Oct 2016.

Figs. $7 \mathrm{a}$ and $7 \mathrm{~d}$. Scanning radar measurements of $Z_{\mathrm{DR}}$ shown in Fig. 7b and, to a lesser extent, in Fig. 7c also indicate a considerable horizontal inhomogeneity of hydrometeor shapes at scales of several kilometers.

Elevation-angle dependencies of DWR can also provide some information on particle shapes. Figure 8 shows DWR measurements as a function of radar elevation angle at a constant close range $(\sim 0.4 \mathrm{~km})$. These measurements correspond to the RHI scans depicted in Fig. 7. It can be seen that for more-spherical particles (Figs. 8a,d), DWR changes with elevation angle are very small. In contrast, for periods with less spherical hydrometeors these changes are quite strong (Figs. 8b,c). This suggests another practical approach for identifying highly nonspherical ice hydrometeors from measurements with scanning radars lacking full polarimetric capability.

Such an approach could be based on analyzing the absolute changes in observed DWR values between slant and near zenith radar viewing. The large magnitude of these changes, (e.g., as in Figs. 8b,c) would indicate a presence of significantly nonspherical ice hydrometeors. Unlike reflectivity values, DWR values are immune to variability in particle concentrations that might exist in radar volumes viewed at different elevation angles. The DWR elevation-angle dependence approach, however, requires a condition that at least at the higher radar frequency particles are large enough (compared to the radar wavelength) so backscatter is no longer proportional to $\nu^{4}$. If this condition is not satisfied, DWR values will be around $0 \mathrm{~dB}$ for all viewing directions given that differential attenuation is negligible or accounted for. For horizontally homogeneous layers of larger hydrometeors, elevation-angle dependencies of W-band reflectivity can also be used as indicators of larger nonspherical particles.

The DWR elevation-angle dependence approach could be applied to scanning radar data from systems lacking a full polarimetric capability such as the first-generation SACRs (Kollias et al. 2014). Even though these SACRs measure linear depolarization ratio (LDR), defined as the ratio of cross-polar and copolar radar returns, LDR has a limited use for identifying shapes of oblate type hydrometeors (e.g., Matrosov et al. 2017). This is because cross-polar radar returns are often below the radar sensitivity level, and (when measurable) strongly depend on particle orientation so LDR elevation-angle trends often are not pronounced. 

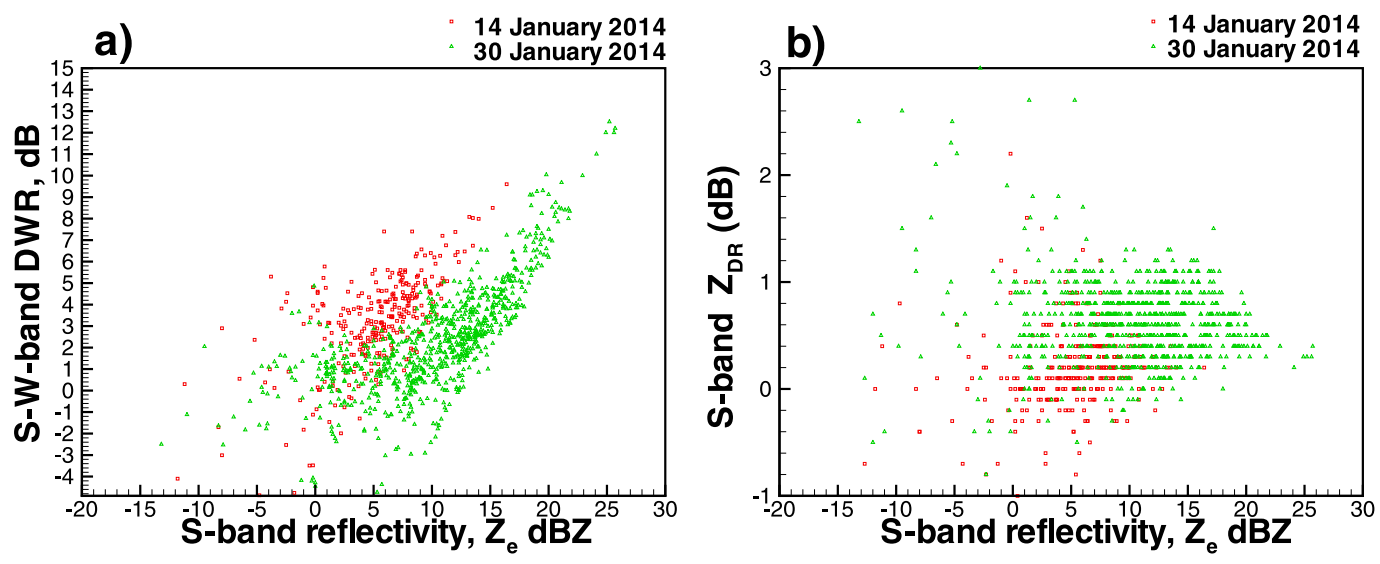

FIG. 9. Scatterplots of (a) S-W band DWR and (b) S-band $Z_{\mathrm{DR}}$ vs S-band reflectivity from collocated KMQT and CloudSat radar measurements for two snowfall events.

\section{Evidence of the DWR particle shape dependence from collocated satellite and operational weather radar measurements}

Satellite radar measurements can be closely collocated in $3 \mathrm{D}$ space and time with ground-based radar measurements. DWR estimates obtained as a result of collocating can provide insights into snow crystal microphysics that are unobtainable using single wavelength radar measurements. As an example of such collocation, Fig. 9a shows DWR as a function of horizontal polarization reflectivity measurements from the operational S-band $(\sim 3 \mathrm{GHz})$ Weather Surveillance Radar-1988 Doppler (WSR-88D) unit located near Marquette, Michigan $\left[46.5311^{\circ} \mathrm{N}\right.$, $87.5487^{\circ} \mathrm{W}$; Next-Generation Radar (NEXRAD) identifier KMQT]. The DWR values shown in this figure are derived from KMQT WSR-88D measurements and the $\mathrm{W}$-band gaseous attenuation-corrected data from the CloudSat satellite nadir-pointing cloud profiling radar. Note that CloudSat radar multiple-scattering effects are partially compensated by snow attenuation (Matrosov and Battaglia 2009). There are practically no zenith enhancements at $\mathrm{S}$ band because particles are usually much smaller than S-band wavelengths $(\lambda \sim 10 \mathrm{~cm})$.

The data depicted in Fig. 9 were collected in two different snowfall events observed in January 2014 near the KMQT site location 16 days apart during the two consecutive CloudSat overpasses. The details of the measurement collocation procedure, which accounts for differing radar-resolution volumes and sampling strategies, is described by Matrosov (2019). WSR-88D data are compiled from volume scans consisting of plan position indicator (PPI) measurements at radar elevation angles between $0.5^{\circ}$ and $4.5^{\circ}$.

It can be seen from Fig. 9a that, similar to $\mathrm{K}_{\mathrm{a}}-\mathrm{W}$-band DWR from the SACR-2 measurements discussed in the previous sections, the S-W-band DWR increase with longer wavelength reflectivity becomes, on average, pronounced when S-band $Z_{e}>0 \mathrm{~dB} Z$. For the 14 January 2014 event, DWR values for the same KMQT reflectivity values are generally greater by several decibels than those for the 30 January 2014 event. Maximum observed DWR values are around $10 \mathrm{~dB}$, somewhat higher than for the SACR-2 $\mathrm{K}_{\mathrm{a}}-\mathrm{W}$ DWR. This is not surprising, however, because the WSR-88D-CloudSat frequency difference is larger than for the SACR-2 frequencies.

Figure $9 \mathrm{~b}$ shows WSR-88D differential reflectivity measurements as a function of S-band reflectivity for these two events. For a given reflectivity level, 30 January 2014 event $Z_{\mathrm{DR}}$ values are on average higher (relative to 14 January 2014 data), which suggests more-nonspherical particles with smaller aspect ratios. Overall, the presented WSR-88D-CloudSat data are consistent with the SACR-2 measurements and indicate a potential utility of combining operational ground-based and spaceborne radar measurements for DWR-based studies of ice hydrometeor microphysics.

\section{Discussion and conclusions}

Theoretical simulations and observations of precipitating ice hydrometeors were used to investigate factors determining dual-wavelength radar ratio. From measurements of a dual-frequency ( $\mathrm{K}_{\mathrm{a}}$ and $\mathrm{W}$ bands) cloud radar deployed at the Oliktok Point DOE ARM facility, it was found that DWR and absolute reflectivity measurements are well correlated (Fig. 1). Corresponding correlation coefficients between DWR and $Z_{e}$, are about 0.7 for $Z_{e}\left(\mathrm{~K}_{\mathrm{a}}\right)>0 \mathrm{~dB} Z$. DWR values for lower reflectivities are often very noisy and of limited use. The maximum $\mathrm{K}_{\mathrm{a}}$-band reflectivities observed in this study were around $20 \mathrm{dBZ}$. The observations are consistent with results of theoretical modeling based on ISDAC particle size distributions. For the $\mathrm{K}_{\mathrm{a}}-\mathrm{W}$-band frequency 
pair commonly used in cloud radars, a relatively strong general increase of DWR with reflectivity is observed when the longer-wavelength $Z_{e}$ values are greater than about $0 \mathrm{~dB} Z$. For pairs of longer wavelengths (e.g., $K_{\mathrm{u}}-\mathrm{K}_{\mathrm{a}}$ bands), such an increase is expected starting at higher reflectivity values. Therefore, corresponding DWR values are significantly smaller, suggesting that the addition of a third (lower) frequency radar measurement is only beneficial for larger hydrometeor populations exhibiting higher reflectivities. A relatively strong correlation between DWR and $Z_{e}$ can be explained, in part, by the fact that both these variables are relatively strongly related to the characteristic particle size representing the entire PSD.

Although for a given size distribution DWR exhibits very little dependence on particle density, the DWR variability with particle aspect ratio (i.e., particle shape) is significant. Theoretical calculations using in situ PSDs and measurements with the vertically pointing dualfrequency radar indicate that for commonly observed ice hydrometeors, the DWR variability with particle shape can be up to about $5-7 \mathrm{~dB}$ or even higher (e.g., between particles with small aspect ratios and morespherical ice hydrometeors). For a given PSD, a general decrease of DWR values with decreasing particle aspect ratios is due to near zenith reflectivity enhancement of W-band backscatter. These results point out to the importance of particle shape assumptions or estimates (e.g., from polarimetric radar measurements) in ice hydrometeor microphysical retrievals based on multifrequency radar measurements.

Although particle degree of nonsphericity changes play an important role in the DWR variability (at a given lower-frequency reflectivity), changes in other microphysical parameters such as the $m-D$ relation coefficients (e.g., Fig. 2b vs Fig. 2e) and the PSD details affect this variability. It results in a significant scatter of DWR data points in Fig. 2 (and also in Fig. 1) for a given value $Z_{e}$. To illustrate the influence of PSD shape on the relation between DWR and $Z_{e}$, model calculations were performed assuming gamma-function PSD, which is characterized by three parameters: the scaling factor $N_{o}$, the PSD shape parameter $\mu$, and the characteristic particle size such as median volume size $D_{\mathrm{mv}}$. In situ measurements conducted in ice clouds and precipitation indicate that the $\mu$ parameter usually varies between -2 and 1 (Matrosov and Heymsfield 2017).

Figure 10 shows modeled DWR $-Z_{e}$ correspondences for different values of $\mu$. In situ measurements indicate that ice water content (IWC) values of around $0.06 \mathrm{~g} \mathrm{~m}^{-3}$ approximately (on average) correspond to $\mathrm{K}_{\mathrm{a}}$-band reflectivities of $\sim 0 \mathrm{dBZ}$ (e.g., Matrosov and Heymsfield 2017). The gamma-function PSD scaling factors for the

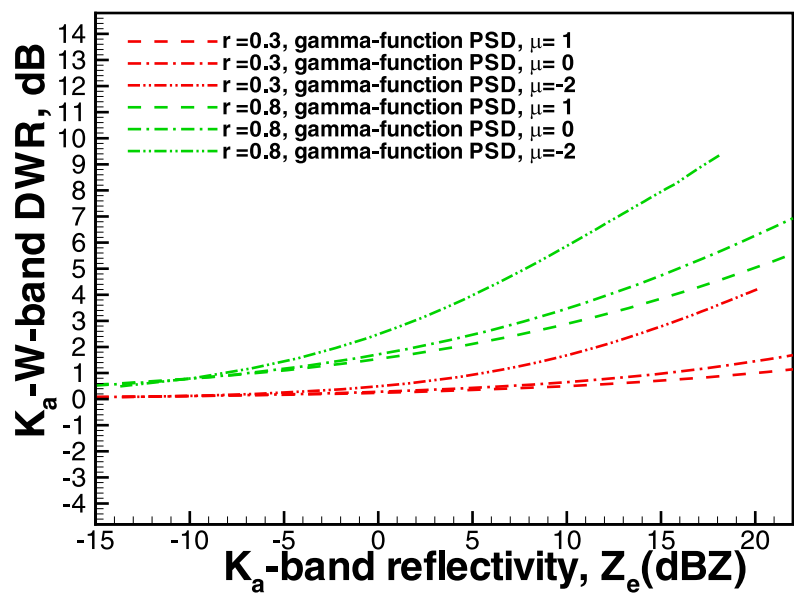

FIG. 10. DWR $-Z_{e}$ correspondences modeled for different types of gamma-function PSDs assuming the $m(\mathrm{~g})=0.0046 D^{2.1}(\mathrm{~cm})$ mass-size relation and different aspect ratios $r$.

illustration in Fig. 10 were chosen based on this average correspondence. $D_{\mathrm{mv}}$ values varied from 0.03 to $0.4 \mathrm{~cm}$. As seen from Fig. 10 results, there is a fair amount of variability in the DWR $-Z_{e}$ relations depending on PSD details. It was found also that the DWR $-Z_{e}$ scatter data calculated using the SSRG method and the T-matrix method (Mishchenko and Travis 1994) (not shown) were also in good agreement. The differences in modeled DWR values (for given a reflectivity value) using these two computational methods typically differed by not more than approximately $2 \mathrm{~dB}$ for larger reflectivities or so (less than that for $Z_{e}<10 \mathrm{~dB} Z$ ).

When hydrometeors are large enough to cause deviations from $\nu^{4}$ backscatter dependency at the higher frequency (i.e., non-Rayleigh scattering), DWR from vertically pointing radar measurements could hypothetically be used to provide information on ice hydrometeor aspect ratios. Untangling the contributions of particle aspect ratios and characteristic size to DWR, however, is needed. This could be done using reflectivity constraints (i.e., utilizing DWR $-Z_{e}$ correspondences) and assuming that there are only limited changes in the particle $m-D$ relation (e.g., Figs. 2a-c). These changes (e.g., Fig. 2b vs Fig. 2e) and the PSD detail variability would complicate the separation of relative contributions of particle aspect ratio and characteristic size. While $m-D$ relation variability is not expected to be strong for unrimed and low-rimed ice hydrometeors (e.g., von Lerber et al. 2017), it still presents a challenge for estimations of particle general shape from vertically pointing DWR measurements. As a result, the ability of DWR $-Z_{e}$ correspondences to provide information on particle shape may be limited to qualitative statements (e.g., particles with high degree of nonsphericity 
vs more-spherical particles) unless the DWR information is integrated into a more comprehensive technique involving additional radar variables allowing estimates of additional influencing factors mentioned above. Observational data shown in Fig. 6 suggest the feasibility of such relatively crude particle shape estimates, though the measurements considered here correspond to unrimed and low-rimed hydrometeors, as indicated by mean vertical Doppler velocity and LWP observations. DWR values for a given $\mathrm{K}_{\mathrm{a}}$-band reflectivity for October 2016 cases in Fig. 1a are on average smaller than those for the May 2017 cases (Fig. 1b). It suggests the existence of particles with larger mean aspect ratios in the latter cases.

Another potentially useful dual-wavelength approach for inferring general ice hydrometeor shape is to leverage the DWR dependencies on radar elevation angle. SACR-2 measurements indicate that highly nonspherical ice particle populations that are large enough to cause deviations from the $\nu^{4}$ backscatter scaling (at least at the higher-frequency band) exhibit strong elevationangle DWR dependence. The lowest DWR values for such particles are observed near vertical beam pointing. For more-spherical particles, observed DWR changes with elevation angle are very small as expected from their more symmetrical shapes. While differential attenuation effects might introduce additional uncertainties when scanning large volumes, at close ranges their influence is not expected to be significant.

The collocation of high-frequency radar measurements from space (i.e., W-band CloudSat radar) with S-band ground-based operational weather radars offers new opportunities for studying ice hydrometeor microphysics. Initial results from such collocations indicate that for a given reflectivity level, S-W DWR values are generally greater for more-nonspherical hydrometeors (as identified by S-band differential reflectivity measurements). This is consistent with the results obtained using the dual-frequency SACR-2 measurements.

Acknowledgments. This work was supported by the U.S. Department of Energy's Atmospheric Systems Research (ASR) program (DE-SC0013306) and NASA Grant NNX16AQ36G.

\section{REFERENCES}

Callaghan, T. V., and Coauthors, 2011: Multiple effects of changes in Arctic snow cover. Ambio, 40, 32-45, https://doi.org/ 10.1007/s13280-011-0213-x.

Chase, R. J., and Coauthors, 2018: Evaluation of triple-frequency radar retrieval of snowfall properties using coincident airborne in situ observations during OLYMPEX. Geophys. Res. Lett., 45, 5752-5760, https://doi.org/10.1029/2018GL077997.
Erfani, E., and D. L. Mitchell, 2017: Growth of ice particle mass and projected area during riming. Atmos. Chem. Phys., 17, 1241-1257, https://doi.org/10.5194/acp-17-1241-2017.

Garrett, T. J., C. Fallgatter, K. Shkurko, and D. Howlett, 2012: Fall speed measurement and high-resolution multi-angle photography of hydrometeors in free fall. Atmos. Meas. Tech., 5, 2625-2633, https://doi.org/10.5194/amt-5-26252012.

Heymsfield, A. J., and C. D. Westbrook, 2010: Advances in the estimation of ice particle fall speeds using laboratory and field measurements. J. Atmos. Sci., 67, 2469-2482, https://doi.org/ 10.1175/2010JAS3379.1.

_ C. Schmitt, and A. Bansemer, 2013: Ice cloud particle size distributions and pressure-dependent terminal velocities from in situ observations at temperatures from $0^{\circ}$ to $-86^{\circ} \mathrm{C}$. J. Atmos. Sci., 70, 4123-4154, https://doi.org/10.1175/JAS-D12-0124.1.

Hogan, R. J., and C. D. Westbrook, 2014: Equation for the microwave backscatter cross section of aggregate snowflakes using the self-similar Rayleigh-Gans approximation. J. Atmos. Sci., 71, 3292-3301, https://doi.org/10.1175/JAS-D-13-0347.1.

- L. Tian, P. R. A. Brown, C. D. Westbrook, A. J. Heymsfield, and J. D. Eastment, 2012: Radar scattering from ice aggregates using the horizontally aligned oblate spheroid approximation. J Appl. Meteor. Climatol., 51, 655-671, https://doi.org/10.1175/ JAMC-D-11-074.1.

Huang, G., V. N. Bringi, A. Newman, G. Lee, D. Moisseev, and B. M. Notaros, 2019: Dual-wavelength radar technique development for snow rate estimation: A case study from GCPEx. Atmos. Meas. Tech., 12, 1409-1427, https://doi.org/ 10.5194/amt-12-1409-2019.

Kneifel, S., A. von Lerber, J. Tiira, D. Moisseev, P. Kollias, and J. Leinonen, 2015: Observed relations between snowfall microphysics and triple-frequency radar measurements. J. Geophys. Res. Atmos., 120, 6034-6055, https://doi.org/ 10.1002/2015JD023156.

Kollias, P., N. Bharadwaj, K. Widener, I. Jo, and K. Johnson, 2014: Scanning ARM cloud radars: Operational sampling strategies. J. Atmos. Oceanic Technol., 31, 569-582, https://doi.org/ 10.1175/JTECH-D-13-00044.1.

Korolev, A. V., and G. A. Isaac, 1999: Ice particle habits in Arctic clouds. Geophys. Res. Lett., 26, 1299-1302, https://doi.org/ 10.1029/1999GL900232.

Leinonen, J., and Coauthors, 2018: Retrieval of snowflake microphysical properties from multifrequency radar observations. Atmos. Meas. Tech., 11, 5471-5488, https://doi.org/10.5194/ amt-11-5471-2018.

Liao, L., R. Meneghini, T. Iguchi, and A. Detwiler, 2005: Use of dual-wavelength radar for snow parameter estimates. J. Atmos. Oceanic Technol., 22, 1494-1506, https://doi.org/ 10.1175/JTECH1808.1.

,,-- L. Tian, and G. M. Heymsfield, 2008: Retrieval of snow and rain from combined $\mathrm{X}$ - and $\mathrm{W}$-band airborne radar measurements. IEEE Trans. Geosci. Remote Sens., 46, 1514 1524, https://doi.org/10.1109/TGRS.2008.916079.

Lu, Y., Z. Jiang, K. Aydin, J. Verlinde, E. Clothiaux, and G. Botta, 2016: A polarimetric scattering database for non-spherical ice particles at microwave wavelengths. Atmos. Meas. Tech., 9, 5119-5134, https://doi.org/10.5194/amt-9-5119-2016.

Maahn, M., 2019: MASC snow particle images. ARM Mobile Facility (OLI) Oliktok Point, Alaska; AMF3 (M1). ARM Data Center, accessed 21 February 2019, https://doi.org/10.5439/ 1497701. 
—_, and U. Löhnert, 2017: Potential of higher-order moments and slopes of the radar Doppler spectrum for retrieving microphysical and kinematic properties of Arctic ice clouds. J. Appl. Meteor. Climatol., 56, 263-282, https://doi.org/ 10.1175/JAMC-D-16-0020.1.

— - — P. Kolias, R. C. Jackson, and G. M. McFarquhar, 2015: Developing and evaluating ice cloud parameterizations for forward modeling of radar moments using in situ aircraft observations. J. Atmos. Oceanic Technol., 32, 880-903, https:// doi.org/10.1175/JTECH-D-14-00112.1.

Marchand, R., G. G. Mace, A. G. Hallar, I. B. McCubbin, S. Y. Matrosov, and M. D. Shupe, 2013: Enhanced radar backscattering due to oriented ice particles at $95 \mathrm{GHz}$ during StormVEx. J. Atmos. Oceanic Technol., 30, 2336-2351, https://doi.org/ 10.1175/JTECH-D-13-00005.1.

Mason, S. L., C. J. Chiu, R. J. Hogan, D. Moisseev, and S. Kneifel, 2018: Retrievals of riming and snow density from vertically pointing Doppler radars. J. Geophys. Res. Atmos., 123, 13 80713 834, https://doi.org/10.1029/2018JD028603

Matrosov, S. Y., 1991: Theoretical study of radar polarization parameters obtained from cirrus clouds. J. Atmos. Sci., $\mathbf{4 8}$, 1062-1070, https://doi.org/10.1175/1520-0469(1991)048<1062: TSORPP $>2.0 . \mathrm{CO} ; 2$.

_ 1993: Possibilities of cirrus particle sizing from dual-frequency radar measurements. J. Geophys. Res., 98, 20 675-20 683, https:// doi.org/10.1029/93JD02335.

_ 1998: A dual-wavelength radar method to measure snowfall rate. J. Appl. Meteor., 37, 1510-1521, https://doi.org/10.1175/ 1520-0450(1998)037<1510:ADWRMT>2.0.CO;2.

_ 2019: Comparative evaluation of snowfall retrievals from the CloudSat W-band radar using ground-based weather radars. J. Atmos. Oceanic Technol., 36, 101-111, https://doi.org/ 10.1175/JTECH-D-18-0069.1.

—_, and Battaglia, 2009: Influence of multiple scattering on CloudSat measurements in snow: A model study. Geophys. Res. Lett., 36, L12806, https://doi.org/10.1029/2009GL038704.

__ and A. J. Heymsfield, 2017: Empirical relations between size parameters of ice hydrometeor populations and radar reflectivity. J Appl. Meteor. Climatol., 56, 2479-2488, https:// doi.org/10.1175/JAMC-D-17-0076.1.

— atmospheric liquid water layers using microwave radiometer measurements. J. Atmos. Oceanic Technol., 35, 1091-1102, https://doi.org/10.1175/JTECH-D-17-0179.1.

— A. A. Heymsfield, and Z. Wang, 2005: Dual-frequency radar ratio of nonspherical atmospheric hydrometeors. Geophys. Res. Lett., 32, L13816, https://doi.org/10.1029/2005GL023210.

_- G. G. Mace, R. Marchand, M. D. Shupe, A. G. Hallar, and I. B. McCubbin, 2012: Observations of ice crystal habits with a scanning polarimetric $\mathrm{W}$-band radar at slant linear depolarization ratio mode. J. Atmos. Oceanic Technol., 29, 989-1008, https://doi.org/10.1175/JTECH-D-11-00131.1.

—_, C. G. Schmitt, M. Maahn, and G. de Boer, 2017: Atmospheric ice particle shape estimates from polarimetric radar measurements and in situ observations. J. Atmos. Oceanic
Technol., 34, 2569-2587, https://doi.org/10.1175/JTECH-D17-0111.1.

Matthews, A., B. Isom, D. Nelson, I. Lindenmaier, J. Hardin, K. Johnson and N. Bharadwaj, 2016a: $\mathrm{K}_{\mathrm{a}}$-Band Scanning ARM Cloud Radar (KASACRVPTHRC), ARM Mobile Facility (OLI) Oliktok Point, Alaska; AMF3 (M1). ARM Data Center, accessed 21 October 2018, https://doi.org/ $10.5439 / 1224840$.

$-,-,-\longrightarrow,-,-$, and $-, 2016 \mathrm{~b}:$ W-band Scanning ARM Cloud Radar (WSACRVPTHRC). ARM Mobile Facility (OLI) Oliktok Point, Alaska; AMF3 (M1). ARM Data Center, accessed 21 October 2018, https://doi.org/ 10.5439/1224850.

McFarquhar, G. M., and Coauthors, 2011: Indirect and SemiDirect Aerosol Campaign: The impact of Arctic aerosols on clouds. Bull. Amer. Meteor. Soc., 92, 183-201, https://doi.org/ 10.1175/2010BAMS2935.1.

Melnikov, V., 2017: Parameters of cloud ice particles retrieved from radar data. J. Atmos. Oceanic Technol., 34, 717-728, https://doi.org/10.1175/JTECH-D-16-0123.1.

Mishchenko, M. I., and L. D. Travis, 1994: T-matrix computations of light scattering by larger spheroidal particles. Opt. Commun., 109, 16-21, https://doi.org/10.1016/0030-4018(94) 90731-5.

Mosimann, L., 1995: An improved method for determining the degree of snow crystal riming by vertical Doppler radar. Atmos. Res., 37, 305-323, https://doi.org/10.1016/0169-8095(94) 00050-N.

Reinking, R. F., S. Y. Matrosov, R. A. Kropfli, and B. W. Bartram, 2002: Evaluation of a $45^{\circ}$ slant quasi-linear radar polarization state for distinguishing drizzle droplets, pristine ice crystals, and less regular ice particles. J. Atmos. Oceanic Technol., 19, 296-321, https://doi.org/10.1175/1520-0426-19.3.296.

Schrom, R. S., and M. R. Kumjian, 2018: Bulk-density representations of branched planar ice crystals: Errors in the polarimetric radar variables. J Appl. Meteor. Climatol., 57, 333-346, https://doi.org/10.1175/JAMC-D-17-0114.1.

Sturm, M., J. Holmgren, and D. K. Perovich, 2002: Winter snow cover on the sea ice of the Arctic Ocean at the Surface Heat Budget of the Arctic Ocean (SHEBA): Temporal evolution and spatial variability. J. Geophys. Res., 107, 8047, https:// doi.org/10.1029/2000JC000400.

Vogel, J. M., and F. Fabry, 2018: Contrasting polarimetric observations of stratiform riming and nonriming events. J Appl. Meteor. Climatol., 57, 457-476, https://doi.org/10.1175/JAMCD-16-0370.1.

von Lerber, A., D. Moisseev, L. F. Bliven, W. Petersen, A. Harri, and V. Chandrasekar, 2017: Microphysical properties of snow and their link to $Z_{e}-S$ relations during BAECC 2014. J. Appl. Meteor. Climatol., 56, 1561-1582, https://doi.org/ 10.1175/JAMC-D-16-0379.1.

Wipf, S., and C. Rixen, 2010: A review of snow manipulation experiments in Arctic and alpine tundra ecosystems. Polar Res., 29, 95-109, https://doi.org/10.1111/j.1751-8369.2010.00153.x. 